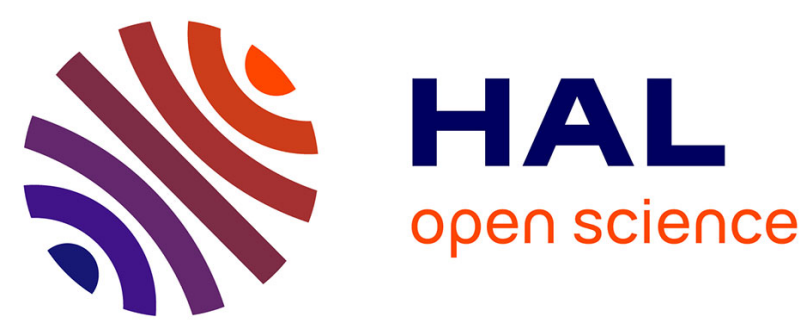

\title{
Intracerebral delivery of 5-iodo-2'-deoxyuridine in combination with synchrotron stereotactic radiation for the therapy of the F98 glioma.
}

Julia Rousseau, Jean-François Adam, Pierre Deman, Ting Di Wu, Jean-Luc

Guerquin-Kern, Barbara Gouget, Rolf F. Barth, François Estève, Hélène

Elleaume

\section{To cite this version:}

Julia Rousseau, Jean-François Adam, Pierre Deman, Ting Di Wu, Jean-Luc Guerquin-Kern, et al.. Intracerebral delivery of 5-iodo-2'-deoxyuridine in combination with synchrotron stereotactic radiation for the therapy of the F98 glioma.. Journal of Synchrotron Radiation, 2009, 16 (Pt 4), pp.573-81. 10.1107/S0909049509016987 . inserm-00410444

\section{HAL Id: inserm-00410444 https://www.hal.inserm.fr/inserm-00410444}

Submitted on 12 Sep 2011

HAL is a multi-disciplinary open access archive for the deposit and dissemination of scientific research documents, whether they are published or not. The documents may come from teaching and research institutions in France or abroad, or from public or private research centers.
L'archive ouverte pluridisciplinaire HAL, est destinée au dépôt et à la diffusion de documents scientifiques de niveau recherche, publiés ou non, émanant des établissements d'enseignement et de recherche français ou étrangers, des laboratoires publics ou privés. 
Synopsis Intracerebral Delivery of 5-Iodo-2'-Deoxyuridine in Combination with Synchrotron Stereotactic Radiation for the Therapy of the F98 Glioma

JULIA ROUSSEAU, JEAN-FRANCOIS ADAM, PIERRE DEMAN, TING-DI WU, JEANLUC GUERQUIN-KERN, BARBARA GOUGET, ROLF F. BARTH, FRANCOIS ESTEVE and HELENE ELLEAUME

Abstract Iodine-enhanced synchrotron stereotactic radiotherapy (SSR) takes advantage of the radiation dose-enhancement produced by high $\mathrm{Z}$ elements when irradiated with monoenergetic beams of synchrotron X-rays. In this study, we have investigated whether therapeutic efficacy could be improved using a thymidine analogue: 5-iodo-2'-deoxyuridine (IUdR), as a radiosentizing agent. IUdR was administered intracerebrally (i.c.) over 6 days to F98 glioma-bearing rats using Alzet $^{\circledR}$ osmotic pumps, beginning 7 days after tumor implantation. On the $14^{\text {th }}$ day, a single 15 Gy dose of $50 \mathrm{keV}$ synchrotron X-rays was delivered to the brain. Animals were followed until the time of death and the primary endpoints of this study were mean and median survival times. The median survival time for irradiation alone, chemotherapy alone or the combination were 44, 32 and 46 days, respectively, compared to 24 days for untreated controls. Each treatment alone significantly increased the rats' survival in comparison with the untreated group. Their combination did not however significantly improve survival compared to that of $\mathrm{X}$-irradiation alone or chemotherapy alone. Further studies are required to understand why the combination of chemo-radiotherapy was no more effective than X-irradiation alone.

\section{Keywords: Glioma; IUdR; Intracerebral delivery; Osmotic pump; Synchrotron; Radiation therapy.}

\section{Introduction}

High grade gliomas are almost uniformly fatal despite aggressive multimodality treatments (Behin et al., 2003, Croteau \& Mikkelsen, 2001). Efforts to improve their prognosis using innovative radiation therapy techniques have included: stereotactic radiosurgery (Phillips et al., 1994), intensity modulated radiation therapy (Cardinale et al., 1998), boron neutron capture therapy (Barth et al., 2005), Auger electron emitter therapy (Kassis, 2003) and synchrotron strereotactic radiotherapy (SSR) (Adam et al., 2003, Adam et al., 2006, Biston et al., 2004, Rousseau, Boudou, Barth et al., 2007). In iodine enhanced-SSR, the tumor is selectively loaded with an iodinated compound and then stereotactically irradiated with a monochromatic beam of $50 \mathrm{keV} \mathrm{X}$-rays, restricted to the tumor volume, as determined by imaging. The resulting radiation geometry produces a sharp dose distribution around the 
tumor. In addition, the fluorescent X-rays, photoelectrons, and Auger electrons generated by the photoelectric effect on the high- $\mathrm{Z}$ element atoms produce a localized dose-enhancement (Rousseau, Boudou, Esteve et al., 2007, Boudou et al., 2005, Boudou et al., 2004). The use of $\mathrm{X}$-rays with energies in the $10-100 \mathrm{keV}$ range is essential for the success of this approach, due to the prevalence of the photoelectric effect at these energies. In contrast, X-rays produced by medical accelerators (5-25 MV), would provide less than 10\% dose-enhancement from the photoelectric effect (Robar et al., 2002). The tunable and intense monochromatic X-ray beams, generated with synchrotron sources, therefore are essential for optimizing the therapeutic efficacy of this treatment. For the irradiation of rats and mice, iodine doseenhancement is maximum for $\mathrm{X}$-ray energies of $\sim 50 \mathrm{keV}$ and can reach $250 \%$ in the presence of an iodine contrast agent at a concentration of $10 \mathrm{mg} / \mathrm{mL}$ (Adam et al., 2003, Corde et al., 2004, Esteve et al., 2002).

We recently have shown that suitable iodine bio-distributions could be obtained in F98 rat glioma, by intracarotid or intravenous (i.v.) infusion of the iodinated contrast agent (Iomeron ${ }^{\circledR}$ ) in combination with the intracarotid infusion of mannitol to transiently disrupt the blood brain barrier (Adam et al., 2005, Adam et al., 2006). A significant improvement in the survival of F98 glioma-bearing rats was obtained when the animals were irradiated in the presence of iodine (doses $\leq 15 \mathrm{~Gy}$ ) compared with irradiation alone (Adam et al., 2006), although no long-term survivors were observed in that study. The failure of iodine-enhanced SSR to cure these rats may have been due to its inability to uniformly produce lethal DNA damage. Since iodinated contrast agents remain in the extra-cellular space (Lorusso et al., 1994), the $17 \mathrm{keV}$ photoelectrons emitted by iodine atoms have a limited range ( $\sim 10 \mu \mathrm{m})$, and produce a small amount of DNA damage. To improve the effectiveness of SSR, we have investigated the possible use of stable iodine, incorporated into the DNA of tumor cells via 5iodo-2'-deoxyuridine (IUdR), in combination with $50 \mathrm{keV}$ X-rays to generate a cascade of Auger electrons (Fairchild et al., 1982). This can be produced by using either radioactive IUdR, labeled with an Auger emitter such as ${ }^{123} \mathrm{I}$ or ${ }^{125} \mathrm{I}$ (Bodei et al., 2003), or stable ${ }^{127} \mathrm{I}-$ IUdR and external X-rays with energies above the K-edge of iodine (Berry \& Kinsella, 2001). It has been shown that $95 \%$ of Auger electrons have energies below $3 \mathrm{keV}$ with high linear energy transfer (LET). These particles would have a greater relative biological effectiveness comparable to that of $\alpha$ particles (Karnas et al., 1999). Monte Carlo simulations have shown that these high-LET particles could produce more than one DNA double-strand break per decay, and therefore they should be lethal to cells that have incorporated IUdR (Terrissol et al., 2004).

Karnas et al. have shown, both theoretically and experimentally, that the optimum energy for obtaining the maximum dose-enhancement in presence of IUdR is not just above the iodine K-edge (33.17 keV) but at a higher energy of $50 \mathrm{keV}$ (Karnas et al. 1999). We have 
come to a similar conclusion using the SQ20B squamous cells pre-treated with nonradioactive IUdR. The optimal energy for producing maximum radio-sensitization was $50 \mathrm{keV}$, and not $33.5 \mathrm{keV}$ (Corde et al., 2004). Due to the very short range of Auger electrons, iodine atoms must be incorporated into the DNA of tumor cells in order to produce DNA damage. Since IUdR is transported through the cell membrane and incorporated into DNA in competition with thymidine (Thd) during the $S$ phase of the cell cycle, it is a very good radiosensitizer. Efficient radio-sensitization has been obtained with Thd analogs and the effect is dependent on both a sufficient uptake of the analog into DNA on a per cell basis, and on maximizing the proportion of cells with Thd replacement (Doiron et al., 1999, Kassis et al., 1998, Kinsella et al., 1987). Prolonged and locoregional administration of radioactive ${ }^{125} \mathrm{I}-$ IUdR was effective in treating the rat 9L gliosarcoma with a 10-20\% cure rate (Kassis et al., 1998). Several clinical trials are underway to evaluate the therapeutic efficiency of this treatment (Bodei et al., 2003). Mairs et al. have shown that a single injection of $0.37 \mathrm{MBq}$ of

${ }^{125} \mathrm{I}$-IUdR in $10 \mu \mathrm{L}$ labeled only $6 \%$ of tumor cells in C6 glioma-bearing rats whereas similar amounts of ${ }^{125} \mathrm{I}-\mathrm{IUdR}$ released from polymer or infused continuously via an osmotic pump labeled $22 \%$ and $34 \%$ of tumor cells, respectively (Mairs et al., 2000). Using xenograft model for a head and neck cancer, Harrington et al. obtained their best results with pegylated liposome-encapsulated IUdR (PLIUdR) administered over 7 days (Harrington et al., 2004).

In the present study, we have evaluated the feasibility and therapeutic potential of SSR combined with locoregional administration of ${ }^{127}$ I-IudR. Total iodine tissular content in rat brain was measured by Inductively Coupled Plasma Mass Spectrometry (ICP-MS) and the intracellular localization of iodine was determined by Nano Secondary Ion Mass Spectroscopy (Nano-SIMS), which is an analytical imaging technique (Guerquin-Kern et al., 2005, Usami et al., 2008).

\section{Materials and Methods}

\subsection{Animals and tumor implantation}

Male Fischer rats (240-280 g) were purchased from Charles River Laboratory (L'Abresles, Rhône, France). All operative procedures and animal care were in conformity with the Guidelines of the French Government (Décret 87-848, $19^{\text {th }}$ of October 1987, licences \# 7593 and \# A38185-10002) and were approved by the European Synchrotron Radiation Facility Ethical Committee. The F98 rat glioma has been propagated both in vitro and in vivo and has proven to be a useful model to evaluate a variety of therapeutic modalities (Barth, 1998). Cells routinely were cultured as monolayers in Dulbecco's Modified Eagle's Medium (DMEM) (Gibco-Invitrogen-France, Cergy-Pontoise, France) supplemented with 10\% fetal bovine serum, penicillin, and streptomycin. For tumor cell implantation, the rats were 
anesthetized by inhalation of isoflurane followed by an intraperitoneal (i.p.) injection of ketamine $64.5 \mathrm{mg} / \mathrm{kg}$ of body weight (b.w.) mixed with xylazine $5.4 \mathrm{mg} / \mathrm{kg}$ of b.w. Supplemental i.p. injections of ketamine and xylazine were administrated, as needed, to maintain sedation. The animals' eyes were lubricated with an ocular lubricant. For these experiments, 1000 F98 cells in $10 \mu \mathrm{L}$ of serum-free DMEM (containing $1 \%$ agarose with a gelling temperature $<30^{\circ} \mathrm{C}$ ) were stereotactically implanted into the right caudate nucleus (3.5 $\mathrm{mm}$ right to the bregma and $5.0 \mathrm{~mm}$ in depth) of the rats. A syringe pump (model KDS 310, GENEQ inc., Montréal, Québec, Canada) was mounted directly on the stereotactic frame (David Kopf Instruments, Tujunga, California, USA) and the syringe (model $702 \mathrm{~N}$, Hamilton) was attached to the pump. A 22s-gauge needle was first inserted, $3.5 \mathrm{~mm}$ to the right of the bregma to a depth of $5.5 \mathrm{~mm}$ from the skull, and then withdrawn to its target depth in the brain $(5.0 \mathrm{~mm}$ from the skull surface), following which F98 cells were injected over 16 seconds. The needle was left in place for an additional 2 minutes and then withdrawn slowly. The burr hole was then filled with bone wax and the operative field was cleaned with betadine before closure of the scalp incision.

\subsection{Chemotherapeutic agents and intracerebral infusion}

Stable dry 5-iodo-2'-deoxyuridine $\left({ }^{127} \mathrm{I}\right.$-IUdR) was obtained from Sigma-Aldrich (Fluka BioChemika). The IUdR powder was first solubilized in di-methyl sulfoxide (DMSO) (Sigma-Aldrich). Sterile water then was added to obtain a final concentration of $20 \mathrm{mg} / \mathrm{mL}$ of IUdR in 50\% DMSO. In our previous studies, it was established that rats tolerated i.c.

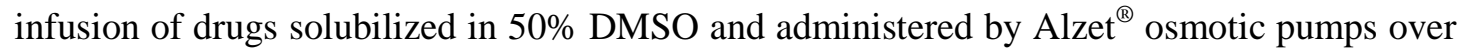
72 hours (Barth et al., 2004). Alzet ${ }^{\circledR}$ osmotic pumps (model \#2001) and Alzet ${ }^{\circledR}$ brain infusion kits (model \#2, rigid stainless-steel cannula, 5mm, 28-gauge) were purchased from Charles River Laboratories (L'Abresles, Rhône, France). The osmotic pumps were filled with the IUdR solution and stored in the dark in a sterile saline (9\%) solution at $37{ }^{\circ} \mathrm{C}$ for 24 hours prior to implantation. Seven days later, the rats were anesthetized as previously described, and the pump was inserted subcutaneously in a pocket created with a hemostat into a mid-scapular incision on the rat's dorsum with a sufficient amount of catheter tubing to permit free motion of the animal's head and neck. The distal end of the catheter was connected to a 28 -gauge brain infusion cannula, which was inserted stereotactically to a depth of $5 \mathrm{~mm}$ from skull surface and the cannula was fixed with surgical glue. The Alzet ${ }^{\circledR}$ pump was left in place from day 7 to day 13 after tumor implantation, during which time the animals received an infusion of ${ }^{127} \mathrm{I}-\mathrm{IUdR}(20 \mathrm{mg} / \mathrm{mL})$, delivered at a rate of $1 \mu \mathrm{L} / \mathrm{h}$. 


\subsection{In vivo uptake of IUdR in F98 glioma-bearing rats}

For Inductively Coupled Plasma Mass Spectrometry (ICP-MS) and Nano Secondary Ion Mass Spectroscopy (Nano-SIMS) analysis, F98 glioma-bearing rats received an i.c. infusion of IUdR delivered by osmotic pumps, as described above.

\subsubsection{ICP-MS: Tissue preparation for iodine quantification}

Following infusion, the animals were euthanized and the brains were removed immediately and stored at $-80^{\circ} \mathrm{C}$ until sample preparation. Five samples of brain were taken: three, contiguous, $2 \mathrm{~mm}$ coronal sections were taken from the tumor area, the second one being located at the injection site. The fourth section was taken from ipsilateral tumor-bearing right hemisphere at the site of tumor implantation, and the last was taken from the contralateral, non-tumor bearing, left, cerebral hemisphere.

Brain samples were dried for 2 days at $60^{\circ} \mathrm{C}$ and weighed. Iodine contents $(\mu \mathrm{g} / \mathrm{g}$ dry weight) were quantified as previously described (Milgram et al., 2008). Briefly, samples were acidified with ultrapure 65\% nitric acid (Normatom quality grade, VWR Prolabo, Fontenay sous Bois, France) and dissolved in ultrapure water. Iodine concentrations were measured using an X7 series quadrupole Thermo Elemental apparatus (Thermo Electron Corporation, Cergy-Pontoise, France) calibrated with a SPEX CertiPrep standard (Jobin Yvon, Longjumeau, France). Rhodium, rhenium and beryllium were used as internal standards $(1 \mu \mathrm{g} / \mathrm{L})$ and the SRM 1640 certified solution (NIST, USA) was analysed at the beginning of each experiment to control the quality of trace elements analysis.

\subsubsection{Nano-SIMS: tissue preparation and analysis}

Imaging by Nano-SIMS was used to assess the subcellular localization of iodine in tumor. Once anesthetised, the rat received an intracardiac perfusion of formaldehyde (4\%) by means of a peristaltic pump (Roth Cyclo II, Roth ${ }^{\circledR}$ ) in order to fix the tissue. The brain then was removed and stored in formaldehyde (Roti ${ }^{\circledR}$ - Histofix 10\%; Roth Sochiel, France), until $1 \mathrm{~mm}^{3}$ samples were cut, corresponding to the injection site. These samples were embedded in an epoxy resin and then cut in $0.300 \mu \mathrm{m}$ serial sections, one of which was stained with toluidine blue for histological examination, and the others were placed on silicon holders for SIMS analysis or on glass slides for light microscopy. The imaging of the iodine atoms was determined using a Nano-SIMS-50 ${ }^{\mathrm{TM}}$ ion nanoprobe (CAMECA, Gennevilliers, France) operated in scanning mode. This technique, based on Secondary Ion Mass Spectrometry (SIMS), allows direct identification of chemical elements with a high degree of sensitivity and specificity and can be used for chemical mapping to visualize the elemental distribution of different atomic species. The instrument is equipped with a magnetic spectrometer using a 
parallel detection system that could acquire simultaneously data up to five atomic species with different masses. The magnetic field is set to detect the heaviest mass (in the present study $\left.\mathrm{m}_{\mathrm{I}}=127\right)$ on one of the largest radius detectors. The other movable detectors were positioned to detect $\mathrm{CN}^{-}, \mathrm{P}^{-}$and $\mathrm{S}^{-}$at the mass respectively of 26,31 and 34 . We have selected the isotope 34 of sulfur rather than the more abundant 32 isotope due to the magnetic field used to detect iodine and the limitation with spacing between adjacent detectors that does not allow simultaneous detection of ${ }^{31} \mathrm{P}$ and ${ }^{32} \mathrm{~S}$. The primary ion beam is generated from a cesium source with an energy of $16 \mathrm{keV}$ and its intensity was around $5 \mathrm{pA}$ for typical experiments, with a probe size of $\sim 150 \mathrm{~nm}$ in diameter (defined as $16-84 \%$ rise distance of the signal intensity). The probe was stepped over the sample in a $256 \times 256$ pixel raster of $40 \mu \mathrm{m}$ to generate secondary ion images. The typical dwell time was $15 \mathrm{~ms} /$ pixel. The image processing was performed using ImageJ, a public domain Java image processing program (Abramoff, 2004) to obtain a proper co-localization of the observed structures on the processed maps for all of the ion species. These processed elemental maps could then be correlated with the light microscope images.

\subsection{Irradiation protocol}

Animals were irradiated with a single $15 \mathrm{~Gy}$ dose of monochromatic X-rays from the European Synchrotron Radiation Facility (ESRF) ID17 beamline, according to the procedure described elsewhere (Adam et al., 2006, Biston et al., 2004). Briefly, the right cerebral hemisphere was centered on the rotational axis and the beam dimensions were adjusted to $10 \mathrm{~mm} \times 1 \mathrm{~mm}$. The complete irradiation was performed with continuous rotation of the rat in 15 adjacent $360^{\circ}$ arcs, so that the planning target volume encompassed a cylinder of $10 \mathrm{~mm}$ in diameter and $15 \mathrm{~mm}$ in height. The prescribed dose of $15 \mathrm{~Gy}$ at the site of the tumor was determined by means of Monte-Carlo simulations (Boudou et al., 2005, Boudou et al., 2004). Rats that received IUdR were irradiated with $50 \mathrm{keV}$ monochromatic X-rays, corresponding to the maximum dose-enhancement observed in vitro (Corde et al., 2004, Karnas et al., 1999). $3 \mathrm{D}$ synchrotron radiation quantitative computed tomography (SRCT) of the rat head was performed before radiation therapy (skin entrance X-ray dose: $0.15-0.20 \mathrm{~Gy}$ ) without the injection of a contrast agent. The images were used for tumor centering and dosimetry. The rats were randomly divided into 4 groups as follow: 1) Untreated controls $(n=17) ; 2){ }^{127} \mathrm{I}$ IUdR injection alone $(\mathrm{n}=12)$; 3) Irradiation alone (15 Gy) on day fourteen after implantation $(\mathrm{n}=8)$; 4) ${ }^{127} \mathrm{I}$-IUdR plus irradiation $(15 \mathrm{~Gy})$, on day fourteen after implantation and $24 \mathrm{~h}$ after completion of the infusion $(n=10)$. 


\subsection{Evaluation of tumor growth by means of Computed Tomography (CT)}

Tumor growth was assessed by SRCT (Rousseau, Boudou, Esteve et al., 2007) in a subset of animals, 15 to 18 days after tumor implantation. CT images were acquired with $35 \mathrm{keV}$ monochromatic X-rays after tail vein injection of $1 \mathrm{~mL}$ of pre-warmed $\left(37^{\circ} \mathrm{C}\right)$ iodinated contrast agent (Iomeron ${ }^{\circledR}$; iodine concentration: $350 \mathrm{mg} / \mathrm{mL}$ ), followed by $1 \mathrm{~mL}$ of $\mathrm{NaCl}$. Three-dimensional axial SRCT images ( $1 \mathrm{~mm}$ slice thickness, $1 \mathrm{~mm}$ spacing) were acquired, starting 5 to 10 minutes after completion of the i.v. iodine infusion. The detector used in this study was made of high-purity germanium, segmented into 432 elements with $0.35 \mathrm{~mm}$ pixel size (Eurisys Mesures ${ }^{\circledR}$, Lingolsheim, France). Image reconstruction was performed using the SNARK89 filtered back projection algorithm (Herman et al., 1989). The images were analyzed using IDL processing software (Interactive Data Language ${ }^{\circledR}$, Research Systems Inc., Boulder, Colorado, U.S.A.).

The iodine concentrations in all voxels of the rat's brain were estimated using:

$$
c=\frac{\left(\mu-\mu_{0}\right)}{\left(\frac{\mu}{\rho}\right)_{E, I}}
$$

where:

- $\mathrm{c}[\mathrm{g} / \mathrm{mL}]$ is the iodine concentration,

- $\mu\left[\mathrm{cm}^{-1}\right]$ is the linear attenuation coefficient measured in the SRCT images after iodine infusion,

- $\mu_{0}\left[\mathrm{~cm}^{-1}\right]$ is the linear attenuation coefficient of rat brain tissue without iodine,

$\mu_{0}$ was measured in several region of interest: $\mu_{0}=0.3149 \pm 0.0001 \mathrm{~cm}^{-1}$ at $35 \mathrm{keV}$.

$(\mu / \rho)_{E, I}$ is the iodine mass attenuation coefficient at energy $E$; in this study $(\mu / \rho)_{35 \mathrm{keV}, \mathrm{I}}=31.23\left[\mathrm{~cm}^{2} / \mathrm{g}\right]$.

The images were acquired $\sim 5 \mathrm{~min}$ after the bolus injection. The tumor size index was computed by a semi-automatic technique. A region of interest (ROI) was grown starting from a seed of voxels that had a value exceeding a given threshold. This was defined as the contralateral brain attenuation coefficient plus three times the noise amplitude. The skull bone ( $\mu=0.68 \mathrm{~cm}^{-1}$ ) was automatically subtracted from the ROI by applying an upper threshold of $0.46 \mathrm{~cm}^{-1}$, a value that empirically never reached the tumor, and corresponded to an iodine concentration $>11.5 \mathrm{mg} / \mathrm{mL}$. The ROIs were visually inspected before being included in the calculation of tumor volume. 


\subsection{Health monitoring of the animals and statistical analysis}

Rats were followed after treatment by weighing them daily and monitoring their food intake, external appearance and locomotion. The combination of sustained weight loss, ataxia, and peri-orbital haemorrhage (Redgate et al., 1991) indicated that death was imminent, and such animals were euthanized by intracardiac injection of Dolethal ${ }^{\circledR}(1 \mathrm{~mL} / \mathrm{kg})$ (Vetoquinol, Lure, France). The survival time was calculated by adding one day to the date of euthanization. Kaplan-Meier survival curves were plotted and pairwise comparisons were made using the Mantel-Cox log rank test (JMP, SAS institute Inc., Cary, NC, U.S.A.). In addition, the percent increase life spans (ILS) relative to the MST and MeST of the untreated control group were computed.

\subsection{Histopathology}

Following death or euthanization, the brains of all rats were removed and then fixed in $10 \%$ buffered formalin. Following fixation, they were cut coronally at the level of the optic chiasm and $2 \mathrm{~mm}$ anterior and posterior to it. Slices were embedded in paraffin, sectioned at 4 $\mu \mathrm{m}$, stained with hematoxylin and eosin (H\&E), and then examined microscopically to assess histopathologic changes. The tumor size index (TSI) was determined from H\&E stained coronal sections, using a semi-quantitative grading scale ranging from 0 to 4 . Each section was scored as follows: 0 , no tumor; 1 , very small (i.e. microscopic, $<1 \mathrm{~mm}) ; 2$, small $(\sim 1-3$ $\mathrm{mm}) ; 3$, large ( 4-7 mm); and 4, massive (>8 mm).

\section{Results}

\subsection{In vivo uptake of IUdR in F98 tumor-bearing rats}

\subsubsection{ICP-MS}

Tissular accumulation of iodine in an F98 tumor-bearing rat brain infused with $20 \mathrm{mg} / \mathrm{mL}$ of IUdR for 6 days at $1 \mu \mathrm{L} / \mathrm{h}$ is shown in Figure 1. Three samples ( $2 \mathrm{~mm}$ thick) of the ispislateral brain were cut $\sim 2 \mathrm{~mm}$ rostal and caudal to the site of infusion. The maximum amount of iodine was found in sections corresponding to the tumor site. Concentration for iodine was $6.04,15.53$ and $35.71 \mu \mathrm{g} / \mathrm{g}$ (dry weight), in the tumor volumes 1,2 and 3 , respectively. The corresponding values for ipsilateral (non tumor area) and contralateral brain were 2.45 and $0.04 \mu \mathrm{g} / \mathrm{g}$, respectively. 


\subsubsection{Nano-SIMS}

Sections stained with toluidine blue (Fig. 2a) were used to control the quality of the blocks and to locate targeted tumor cells for further analysis. Ultrastructural details like the nuclei, nucleoli, nuclear envelopes and intracellular structures are visible on $\mathrm{CN}^{-}$image (Fig. 2b). The $\mathrm{P}^{-}$image is representative of phosphorylated macromolecules, corresponding mainly to nucleic acids, and permits to identify mainly the nuclei (Fig. 2c). The location of $S$ atoms (Fig. 2d) corresponds mostly to the location of proteins in the cell (cytoplasm, nucleus and mostly membranes). Detection of iodine is presented on Figure 2e. The simultaneous detection of $\mathrm{CN}^{-}, \mathrm{P}^{-}$and $\mathrm{S}^{-}$ions permits to identify the location of iodine in the cells. It appears that iodine is aggregated only in the nuclei. Furthermore, iodine is accumulated in condensed chromatin located on the internal nuclear membrane. No iodine was detected either in the cytoplasm or in the extracellular medium.

\subsection{Therapeutic response}

The survival data are summarized in Table 1. Implantation of $10^{3} \mathrm{~F} 98$ glioma cells resulted in the death of all untreated animals. The corresponding Kaplan-Meier plots are shown in Fig. 3. The proportional hazards assumption was checked by comparing the 4 groups overall (a single log-rank test for the 4 curves, $\mathrm{p}<0.001$ ). The statistical tests results are summarized in Table 2. The MeSTs of untreated rats $(24 \mathrm{~d})$ and those that received ${ }^{127} \mathrm{I}-\mathrm{IUdR}$ alone $(32 \mathrm{~d})$ were significantly different $(\mathrm{p}=0.002)$. The MeST of rats that received ${ }^{127} \mathrm{I}-\mathrm{IUdR}$ in combination with X-irradiation (46 d), however, was not statistically different $(p=0.104)$ from that of rats treated with ${ }^{127} \mathrm{I}$-IUdR alone $(32 \mathrm{~d})$. The log-rank test was not used to test the difference between ${ }^{127} \mathrm{I}$-IUdR in combination with radiation and irradiation alone $(\mathrm{MeST}=44$ d), since the survival plots crossed each other. In such cases the log-rank test is unlikely to detect differences between groups (Klein \& Moeschberger, 2003).

\subsection{Computed tomographic imaging}

CT images of two representative animals are shown in Fig. 4 (slice thickness: $1 \mathrm{~mm}$, rats imaged 17 or $18 \mathrm{~d}$ after tumor implantation). The tumor was clearly visible on $6 \mathrm{CT}$ scans of an untreated animal (Fig. 4A) with a tumor size of $\sim 180 \mathrm{~mm}^{3}$. On the other hand, the tumor was not detectable when the rats received IUdR alone treatment over 6 days (Fig. 4B). The tumor volumes were calculated in a subset number of animals in each group. All the treatments: chemotherapy alone, irradiation alone, or their combination lead to a decrease of the tumor growth as shown in Fig. 5. 


\subsection{Neuropathologic evalutation}

Untreated control rats had large, (TSI $=3.4$ ) highly invasive tumors that had the characteristic appearance of the F98 glioma (Clendenon et al., 1990). Animals that received

${ }^{127} \mathrm{I}$-IUdR alone, administered by Alzet ${ }^{\circledR}$ osmotic pumps, generally had smaller tumors (TSI = 2.33 ) with one out of eight rats being tumor free. The brain of this animal had a microscopic porencephalic cyst surrounded by atypical non-proliferating tumor cells in the white matter. Another animal had a tumor, as well as an abscess composed of polymorphonuclear leukocytes and macrophages. Rats that received ${ }^{127} \mathrm{I}-\mathrm{IUdR}$ administered by Alzet ${ }^{\circledR}$ osmotic pumps, in combination with a single $15 \mathrm{~Gy}$ dose of $\mathrm{X}$-irradiation all had tumors (TSI = 3.0). Many of these were subcortical, and a few extended into the leptomeningeal space. A small brain abscess, not contiguous with the tumor, was seen in the brain of one rat. There were no changes suggestive of either a drug or radiation effect.

\section{Discussion}

In the present study, we have evaluated prolonged i.c. infusion of ${ }^{127} \mathrm{I}-\mathrm{IUdR}$ as a radiosensitizer for iodine-enhanced SSR. Auger cascades can be induced by photo-activation of stable iodine with an external X-ray beam tuned at the appropriate energy (Fairchild et al., 1982, Karnas et al., 2001, Karnas et al., 1999), providing that a sufficient amount of iodine has been incorporated in the tumor cells. In addition, since Auger electrons have a relatively short paths in tissue (Karnas et al., 2001, Moiseenko et al., 2002), the iodine atoms have to be located close to nucleus.

Karnas et al. have evaluated the macroscopic dose-enhancement ratio (defined as the ratio of mass energy absorption coefficients for IUdR-DNA to that of DNA) for monoenergetic Xrays and for varying levels of thymidine substitution. For $50 \mathrm{keV} \mathrm{X}$-rays, they found a doseenhancement ratio of 2, with $20 \%$ thymidine replacement (Karnas et al., 1999). The in vitro results that we obtained in a previous study (Corde et al., 2004) were found to be in good agreement with those theoretical dose-enhancement estimations. Recently, Karnas and his collaborators have used Monte Carlo methods to model the initial DNA damages from Auger electron emission from stable iodine atoms incorporated in DNA (Karnas et al., 2001). Using $50 \mathrm{keV} \mathrm{X}$-rays and 20\% thymidine substitution, they estimated the number of double strand breaks (DSBs) from Auger cascades to be 1.86 per Gy. In comparison with the usual yields of DSBs for X-ray irradiation of about 30 DSBs/Gy (Prise et al., 1998), the number of initial DSBs due to Auger cascades is quite small, of the order of $10 \%$, but the complex nature of these DSBs is supposed to make them difficult to repair. 
In the present study, the average iodine concentration in the tumor area was $19 \mu \mathrm{g} / \mathrm{g}$ (dry weight) measured by ICP-MS. This is about 500 and 8 times more than in the contralateral brain and ipsilateral brain, respectively. We verified by Nano-SIMS that the iodine was mainly accumulated in the cell nuclei. Using prolonged infusion of IUdR, we expected to obtain about $20 \%$ of thymidine replacement by IUdR (Lawrence et al., 1990, Rodriguez et al., 1994). The main endpoint of this study was the prolongation in the survival time of F98 glioma-bearing rats following treatment. ${ }^{127} \mathrm{I}-\mathrm{IUdR}$ alone significantly improved the MeST compared to untreated controls ( $32 \mathrm{~d}$ versus $24 \mathrm{~d}, \mathrm{p}=0.002$ ). CT images taken on day 18 following tumor implantation showed almost complete disappearance of the tumor following ${ }^{127} \mathrm{I}$-IUdR administration. Unexpectedly, the combination of ${ }^{127} \mathrm{I}$-IUdR with X-irradiation, did not significantly improve the MeST compared to X-irradiation alone or ${ }^{127} \mathrm{I}-\mathrm{IUdR}$ alone $(92 \%$ ILS, 83\% ILS, and 33\% ILS, respectively). Twenty percent of the animals that received IUdR and $\mathrm{X}$-irradiation survived longer than the irradiated group, but there was only an $8 \%$ difference in \%ILS. A few rats in the group that received ${ }^{127} \mathrm{I}-\mathrm{IUdR}+\mathrm{X}$-irradiation died before the first animals in the $\mathrm{X}$-irradiation alone group, suggesting enhanced toxicity of the combination.

These results can be compared with those reported in the literature, using either radioactive ${ }^{125} \mathrm{I}$-IUdR or the photo-activation of stable IUdR. The Auger effect produced by ${ }^{125} \mathrm{I}$ is however different from the Auger effect induced by $\mathrm{K}$ shell ionization of stable iodine, as in the present work. The Auger effect in ${ }^{125} \mathrm{I}$ is indeed a double effect. The first results from the electron capture by the nucleus (in excess of protons) that induces a $\mathrm{K}$ shell vacancy, and the second from the internal conversion of the resulting nuclei (Tellurium), resulting in a gamma ray emission that will trigger again the Auger effect. Hence the Auger effect in ${ }^{125}$ I is much stronger in energy release and in the number of emitted electrons than the Auger effect resulting from the inner-shell excitation of stable iodine.

Kassis et al. evaluated the therapeutic potential of Auger electron therapy using radioactive ${ }^{125} \mathrm{I}-\mathrm{IUdR}$ in rats bearing intracerebral $9 \mathrm{~L}$ gliosarcoma. In their study, ${ }^{125} \mathrm{I}-\mathrm{IUdR}$ was infused i.c. $(100 \mu \mathrm{l} /$ week, $238 \mu \mathrm{Ci}$ in $86 \mu \mathrm{l})$ over $6 \mathrm{~d}$, using Alzet ${ }^{\circledR}$ osmotic pumps (Kassis et al., 1998). The MeST of rats treated with ${ }^{125} \mathrm{I}$-IUdR was $28.5 \mathrm{~d}$, which was slightly, but not significantly longer ( $\mathrm{p}=0.07)$ than that of control animals $(24 \mathrm{~d})$. However, even with a $22 \%$ ILS , $10 \%$ of the animals survived $>65 \mathrm{~d}$. There are few studies dealing with i.c. tumor treated with stable IUdR in combination with irradiation (Deutsch et al., 1989, Harrington et al., 2004, Kinsella et al., 1987, Kinsella et al., 1998, Williams et al., 1997, Mairs et al., 2000, Deutsch et al., 1990). Deutsch et al. reported on the efficacy of IUdR as a radiosensitizer when administered into the cerebral spinal fluid of the lateral ventricles of 9L gliosarcomabearing rats. In their study, radiotherapy was delivered over the entire brain in three, 8 Gy 
fractions, delivered on days 4, 6 and 7 following 9L tumor implantation. IUdR (8.4 mg) was administered via osmotic pumps over 7 days, beginning on the day of tumor implantation. There was a slight but not statistically significant increase in MeST of treated animals (21.5 d for IUdR alone and $19.5 \mathrm{~d}$ for radiotherapy alone) compared to untreated controls (16.9 d). The combination of radiation and infusion of IUdR significantly enhanced the MeST (30.5 d) compared to all the other groups (Deutsch et al., 1990). Harrington et al. have reported on the effects of radiation therapy with ${ }^{137} \mathrm{Cs}$ in combination with various schedules of administration of free IUdR or pegylated liposomal IUdR (PLIUdR) for the treatment of KB xenografts in nude mice (Harrington et al., 2004). They showed that when PLIUdR was delivered by a prolonged infusion schedule over $7 \mathrm{~d}(48 \mathrm{mg} / \mathrm{kg})$, the therapeutic effect of a single 4.5 Gy fraction, but not for 9 Gy radiotherapy, significantly improved survival. Survival was further enhanced using fractionated PLIUdR- ${ }^{137} \mathrm{Cs}$ radiotherapy, compared to radiotherapy alone. Similarly, Doiron et al. used bromodeoxyuridine (BUdR), another Thd analog. They reported that there was no radiosensitization following a single 16.5 Gy dose in the murine RIF-1 tumor model after intratumoral administration of BUdR polymer. On the other hand, significant radiosensitization was observed following fractionated irradiation $\left({ }^{60} \mathrm{Co}\right.$ gamma rays) when the BUdR polymer was implanted $3 \mathrm{~d}$ prior to the first dose (Doiron et al., 1999).

Using the same tumor model and extracellular iodine as a radio-enhancer (Adam et al., 2006), we obtained survival data similar to those reported in the present study. Rats that received i.v. iodine and intracarotid mannitol in combination with a single $50 \mathrm{keV}, 15 \mathrm{~Gy}$ dose of X-irradiation had a longer MeST than the rats irradiated without iodine (26 d, $46 \mathrm{~d}$, $54 \mathrm{~d}$ and $71 \mathrm{~d}$, for untreated animals, irradiation alone, or in combination with i.v. and intracarotid injections, respectively). In comparison with the $15 \mathrm{~Gy}$ irradiation alone group, the MeSTs were significantly different only for intracarotid infusion $(p=0.2$ and $p=0.004$ for i.v. and intracarotid injections, respectively). The use of stable IUdR rather than radioactive IUdR could be advantageous for protecting surrounding normal brain. Although radioactive IUdR therapy can specifically target cancer cells, it also damages other tissues that take up the radionucleotide. The use of stable IUdR with an external beam would lead to larger irradiation fields, but would be limited to the organs present in these fields. The photoactivation of IUdR theoretically generates additional double strand breaks in DNA (Terrissol et al., 2004). However, it is difficult to differentiate in vivo between the chemotherapeutic effect of IUdR and the interaction of X-rays on the iodine atoms. The chemotherapeutic effect of IUdR observed in this study is important (Table 1) and might mask the Auger effect. The cause of the early deaths observed in the group of rats that received the combination of IUdR and radiotherapy also requires further investigation. In conclusion, although the chemotherapeutic effect of prolonged infusion of ${ }^{127} \mathrm{I}-\mathrm{IUdR}$ produced significant prolongation 
in MeST, the addition of X-ray radiation did not further improve survival. These findings suggest that additional studies are needed to optimize this chemoradiotherapeutic approach for the treatment of brain tumors. 
Table 1 Survival times of F98 glioma-bearing rats after chemo-radiotherapy. ${ }^{127} \mathrm{IUdR}(20 \mathrm{mg} / \mathrm{mL})$ was injected by the means of osmotic pumps starting on day 7 after tumor implantation. The infusion lasted for 6 days, at a rate of $1 \mu \mathrm{L} / \mathrm{h}$. Radiotherapy (single fraction of $15 \mathrm{~Gy}$ ), was delivered on day 14 after inoculation of 1000 F98 glioma cells. ${ }^{*}$ SE is the standard error of the mean.

\begin{tabular}{lllllll}
\hline & \multicolumn{3}{c}{ Survival time (days) } & & \multicolumn{2}{c}{ ILS } \\
\cline { 2 - 4 } \cline { 6 - 7 } & Survival Range & Mean \pm SE* & Median & & Mean & Median \\
\hline Untreated (n=17) & $18-29$ & $23 \pm 1$ & 24 & & - \\
${ }^{127}$ IUdR (n=12) & $17-54$ & $35 \pm 4$ & 32 & & $52 \%$ & $33 \%$ \\
Irradiation 15 Gy (n=8) & $31-57$ & $44 \pm 3$ & 44 & & $91 \%$ & $83 \%$ \\
${ }^{127}$ IUdR + Irradiation 15 Gy (n=10) & $18-69$ & $44 \pm 6$ & 46 & & $91 \%$ & $92 \%$ \\
\hline
\end{tabular}

Table 2 Log-Rank and Wilcoxon statistical tests results. ${ }^{\#}$ N.A.: Not applicable. The tests were not performed since the survival plots cross each other. In that case they are unlikely to detect differences between groups.

\begin{tabular}{|c|c|c|}
\hline \multirow{2}{*}{ Groups comparison } & \multicolumn{2}{|c|}{ Statistical test } \\
\hline & Log-Rank & Wilcoxon \\
\hline IUdR / Untreated & 0.002 & 0.013 \\
\hline X / Untreated & $<0.001$ & $<0.001$ \\
\hline IUdR + X / Untreated & $<0.001$ & 0.003 \\
\hline IUdR + X / IUdR & 0.104 & 0.213 \\
\hline $\mathrm{IUdR}+\mathrm{X} / \mathrm{X}$ & N.A. ${ }^{\#}$ & N.A. ${ }^{\#}$ \\
\hline
\end{tabular}


Figure captions

Figure 1 Tissular accumulation of iodine measured by ICP-MS. Iodine concentrations ( $\mu \mathrm{g} / \mathrm{g}$ dry weight) were measured in a F98 tumor-bearing rat brain infused with $20 \mathrm{mg} / \mathrm{mL}$ of IUdR for 6 days at $1 \mu \mathrm{L} / \mathrm{h}$. Three contiguous, $2 \mathrm{~mm}$ coronal sections of the ipsilateral brain were taken from the tumor area, the second one being located at the injection site (Tumor $2 *$ ). The fourth section was taken from ipsilateral tumor-bearing right hemisphere at the site of tumor implantation, and the last was taken from the contralateral, non-tumor bearing, left, cerebral hemisphere.

Figure 2 Iodine location at the subcellular level determined by Nano-SIMS analysis. The F98 glioma-bearing rat received an intratumoral injection of IUdR during 6 days by the means of osmotic pump. Panel (a), corresponds to a light microscopy view of a brain section stained with toluidine blue. The underlined part in panel (a) is the tumor brain area chosen for Nano-SIMS analysis. The panels (b), (c), (d) and (e) represent the corresponding Nano-SIMS analysis of respectively $\mathrm{CN}^{-}, \mathrm{P}^{-}, \mathrm{S}^{-}$and $\mathrm{I}^{-}$ions in this tumor brain area. Grey scale: white is corresponding to low concentrations or absence of the ion detected; black is corresponding to high concentrations of the ion detected.

Figure 3 Kaplan Meier survival curves for F98 glioma-bearing rats after chemo-radiotherapy. Survival times in days after tumor implantation have been plotted for untreated animals $(x)$, infusion of ${ }^{127} \mathrm{IUdR}$ with osmotic pump $20 \mathrm{mg} / \mathrm{mL}$ alone $(\triangle$ ), irradiation alone (single fraction of $15 \mathrm{~Gy})(\square$ ), or

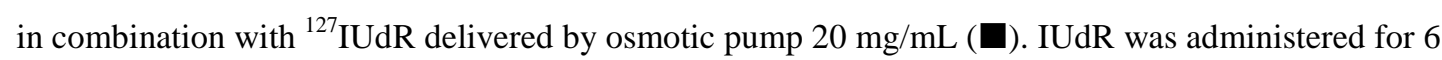
days starting 7 days after tumor implantation. X-ray dose was delivered in a single fraction on day 14 after tumor implantation. Note: in the IUdR group, 2 rats died at the anesthesia and were not included in the analysis.

Figure 4 Synchrotron Computed Tomography. Ten consecutive CT images (slice thickness: $1 \mathrm{~mm}$ ) of the rat head of two representative animals: A) Untreated animal, imaged 18 days after tumor implantation, survival time: 21 days; the tumor is clearly visible on six slices with a tumor size index of $\approx 180 \mathrm{~mm}^{3}$. B) Group "IUdR alone"; imaged on day $17^{\text {th }}$ after tumor implantation; survival time: 51 days. The tumor was no longer detectable after IUdR infusion over 6 days (B), even with an optimized gray level windowing.

Figure 5 Tumor growth versus time for the different treatments. Tumor volumes measured using the CT images for a subset of rats in each group: Untreated animals $(\times) n=11$, infusion of ${ }^{127}$ IUdR with osmotic pump $20 \mathrm{mg} / \mathrm{mL}$ alone $(\triangle) \mathrm{n}=6$, irradiation alone (single fraction of $15 \mathrm{~Gy})(\square) \mathrm{n}=5$, or in combination with ${ }^{127} \mathrm{IUdR}$ with osmotic pump $20 \mathrm{mg} / \mathrm{mL}(\mathbf{\square}) \mathrm{n}=5$. IUdR was administrated for 6 days starting 7 days after tumor implantation. The line corresponds to an exponential fit of the "untreated group" survival data. 
Acknowledgements We thank the European Synchrotron Radiation Facility medical beamline for providing the necessary beam time and technical assistance in all the steps of the experimental studies. We also thank Mrs. C. Massart, Mr. T. Brochard, Dr. C. Nemoz, Mrs. G. Michel-Amadry, Dr. M. Fernandez and Mrs. E. Kerboul for their technical assistance, Mr. D. Dallery for animal care and Mrs. L. Martz for secretarial assistance.

\section{References}

Abramoff, M. D., Magelhaes, P.J., Ram, S.J. (2004). Biophotonics International 11, 36-42.

Adam, J. F., Biston, M. C., Joubert, A., Charvet, A. M., Le Bas, J. F., Esteve, F. \& Elleaume, H. (2005). Int J Radiat Oncol Biol Phys 61, 1173-1182.

Adam, J. F., Elleaume, H., Joubert, A., Biston, M. C., Charvet, A. M., Balosso, J., Le Bas, J. F. \& Esteve, F. (2003). Int J Radiat Oncol Biol Phys 57, 1413-1426.

Adam, J. F., Joubert, A., Biston, M. C., Charvet, A. M., Peoc'h, M., Le Bas, J. F., Balosso, J., Esteve, F. \& Elleaume, H. (2006). Int J Radiat Oncol Biol Phys 64, 603-611.

Barth, R. F. (1998). J Neurooncol 36, 91-102.

Barth, R. F., Coderre, J. A., Vicente, M. G. \& Blue, T. E. (2005). Clin Cancer Res 11, 3987-4002.

Barth, R. F., Yang, W., Al-Madhoun, A. S., Johnsamuel, J., Byun, Y., Chandra, S., Smith, D. R., Tjarks, W. \& Eriksson, S. (2004). Cancer Res 64, 6287-6295.

Behin, A., Hoang-Xuan, K., Carpentier, A. F. \& Delattre, J. Y. (2003). Lancet 361, 323-331.

Berry, S. E. \& Kinsella, T. J. (2001). Semin Radiat Oncol 11, 300-315.

Biston, M. C., Joubert, A., Adam, J. F., Elleaume, H., Bohic, S., Charvet, A. M., Esteve, F., Foray, N. \& Balosso, J. (2004). Cancer Res 64, 2317-2323.

Bodei, L., Kassis, A. I., Adelstein, S. J. \& Mariani, G. (2003). Cancer Biother Radiopharm 18, 861877.

Boudou, C., Balosso, J., Esteve, F. \& Elleaume, H. (2005). Phys Med Biol 50, 4841-4851.

Boudou, C., Biston, M. C., Corde, S., Adam, J. F., Ferrero, C., Esteve, F. \& Elleaume, H. (2004). Phys Med Biol 49, 5135-5144.

Cardinale, R. M., Benedict, S. H., Wu, Q., Zwicker, R. D., Gaballa, H. E. \& Mohan, R. (1998). Int J Radiat Oncol Biol Phys 42, 431-436.

Clendenon, N. R., Barth, R. F., Gordon, W. A., Goodman, J. H., Alam, F., Staubus, A. E., Boesel, C. P., Yates, A. J., Moeschberger, M. L., Fairchild, R. G. \& et al. (1990). Neurosurgery 26, 4755.

Corde, S., Joubert, A., Adam, J. F., Charvet, A. M., Le Bas, J. F., Esteve, F., Elleaume, H. \& Balosso, J. (2004). Br J Cancer 91, 544-551.

Croteau, D. \& Mikkelsen, T. (2001). Curr Treat Options Oncol 2, 507-515.

Deutsch, M., Rewers, A. B., Redgate, E. S., Fisher, E. R. \& Boggs, S. S. (1989). J Natl Cancer Inst 81, 1322-1325.

Deutsch, M., Rewers, A. B., Redgate, S., Fisher, E. R. \& Boggs, S. S. (1990). Int J Radiat Oncol Biol Phys 19, 85-87.

Doiron, A., Yapp, D. T., Olivares, M., Zhu, J. X. \& Lehnert, S. (1999). Cancer Res 59, 3677-3681.

Esteve, F., Corde, S., Elleaume, H., Adam, J. F., Joubert, A., Charvet, A. M., Biston, M. C., Balosso, J. \& Le Bas, J. F. (2002). Acad Radiol 9 Suppl 2, S540-543.

Fairchild, R. G., Brill, A. B. \& Ettinger, K. V. (1982). Invest Radiol 17, 407-416.

Guerquin-Kern, J. L., Wu, T. D., Quintana, C. \& Croisy, A. (2005). Biochim Biophys Acta 1724, 228238.

Harrington, K. J., Syrigos, K. N., Uster, P. S., Zetter, A., Lewanski, C. R., Gullick, W. J., Vile, R. G. \& Stewart, J. S. (2004). Br J Cancer 91, 366-373.

Herman, G. T., Lewitt, R. M., Odhner, D. \& Rowland, S. W. (1989). Report MIPG 160. Medical Imaging Processing Group, Department of Radiology.

Karnas, S. J., Moiseenko, V. V., Yu, E., Truong, P. \& Battista, J. J. (2001). Radiat Environ Biophys 40, 199-206.

Karnas, S. J., Yu, E., McGarry, R. C. \& Battista, J. J. (1999). Phys Med Biol 44, 2537-2549.

Kassis, A. I. (2003). J Nucl Med 44, 1479-1481.

Kassis, A. I., Wen, P. Y., Van den Abbeele, A. D., Baranowska-Kortylewicz, J., Makrigiorgos, G. M., Metz, K. R., Matalka, K. Z., Cook, C. U., Sahu, S. K., Black, P. M. \& Adelstein, S. J. (1998). J Nucl Med 39, 1148-1154. 
Kinsella, T. J., Dobson, P. P., Mitchell, J. B. \& Fornace, A. J., Jr. (1987). Int J Radiat Oncol Biol Phys 13, 733-739.

Kinsella, T. J., Kunugi, K. A., Vielhuber, K. A., Potter, D. M., Fitzsimmons, M. E. \& Collins, J. M. (1998). Clin Cancer Res 4, 99-109.

Klein, J. P. \& Moeschberger, M. L. (2003). Survival analysis techniques for censored and truncated data, 2nd ed. New York: Springer.

Lawrence, T. S., Davis, M. A., Maybaum, J., Stetson, P. L. \& Ensminger, W. D. (1990). Int J Radiat Oncol Biol Phys 18, 1393-1398.

Lorusso, V., Luzzani, F., Bertani, F., Tirone, P. \& de Haen, C. (1994). Eur J Radiol 18 Suppl 1, S1320.

Mairs, R. J., Wideman, C. L., Angerson, W. J., Whateley, T. L., Reza, M. S., Reeves, J. R., Robertson, L. M., Neshasteh_Riz, A., Rampling, R., Owens, J., Allan, D. \& Graham, D. I. (2000). British Journal of Cancer 82, 74-80.

Milgram, S., Carriere, M., Thiebault, C., Malaval, L. \& Gouget, B. (2008). Toxicology 250, 62-69.

Moiseenko, V. V., Karnas, S. J., Yu, E. \& Battista, J. J. (2002). Radiat Prot Dosimetry 99, 113-116.

Phillips, M. H., Stelzer, K. J., Griffin, T. W., Mayberg, M. R. \& Winn, H. R. (1994). J Clin Oncol 12, 1085-1099.

Prise, K. M., Ahnstrom, G., Belli, M., Carlsson, J., Frankenberg, D., Kiefer, J., Lobrich, M., Michael, B. D., Nygren, J., Simone, G. \& Stenerlow, B. (1998). Int J Radiat Biol 74, 173-184.

Redgate, E. S., Deutsch, M. \& Boggs, S. S. (1991). Lab Anim Sci 41, 269-273.

Robar, J. L., Riccio, S. A. \& Martin, M. A. (2002). Phys Med Biol 47, 2433-2449.

Rodriguez, R., Ritter, M. A., Fowler, J. F. \& Kinsella, T. J. (1994). Int J Radiat Oncol Biol Phys 29, 105-113.

Rousseau, J., Boudou, C., Barth, R. F., Balosso, J., Esteve, F. \& Elleaume, H. (2007). Clin Cancer Res 13, 5195-5201.

Rousseau, J., Boudou, C., Esteve, F. \& Elleaume, H. (2007). Int J Radiat Oncol Biol Phys 68, 943-951. Terrissol, M., Edel, S. \& Pomplun, E. (2004). Int J Radiat Biol 80, 905-908.

Usami, N., Furusawa, Y., Kobayashi, K., Lacombe, S., Reynaud-Angelin, A., Sage, E., Wu, T. D., Croisy, A., Guerquin-Kern, J. L. \& Le Sech, C. (2008). Int J Radiat Biol 84, 603-611.

Williams, J. A., Dillehay, L. E., Tabassi, K., Sipos, E., Fahlman, C. \& Brem, H. (1997). J Neurooncol 32, 181-192. 
Figure 1 Tissular accumulation of iodine measured by ICP-MS. Iodine concentrations ( $\mu \mathrm{g} / \mathrm{g}$ dry weight) were measured in a F98 tumor-bearing rat brain infused with $20 \mathrm{mg} / \mathrm{mL}$ of IUdR for 6 days at $1 \mu \mathrm{L} / \mathrm{h}$. Three contiguous, $2 \mathrm{~mm}$ coronal sections of the ipsilateral brain were taken from the tumor area, the second one being located at the injection site (Tumor $2^{*}$ ). The fourth section was taken from ipsilateral tumor-bearing right hemisphere at the site of tumor implantation, and the last was taken from the contralateral, non-tumor bearing, left, cerebral hemisphere.

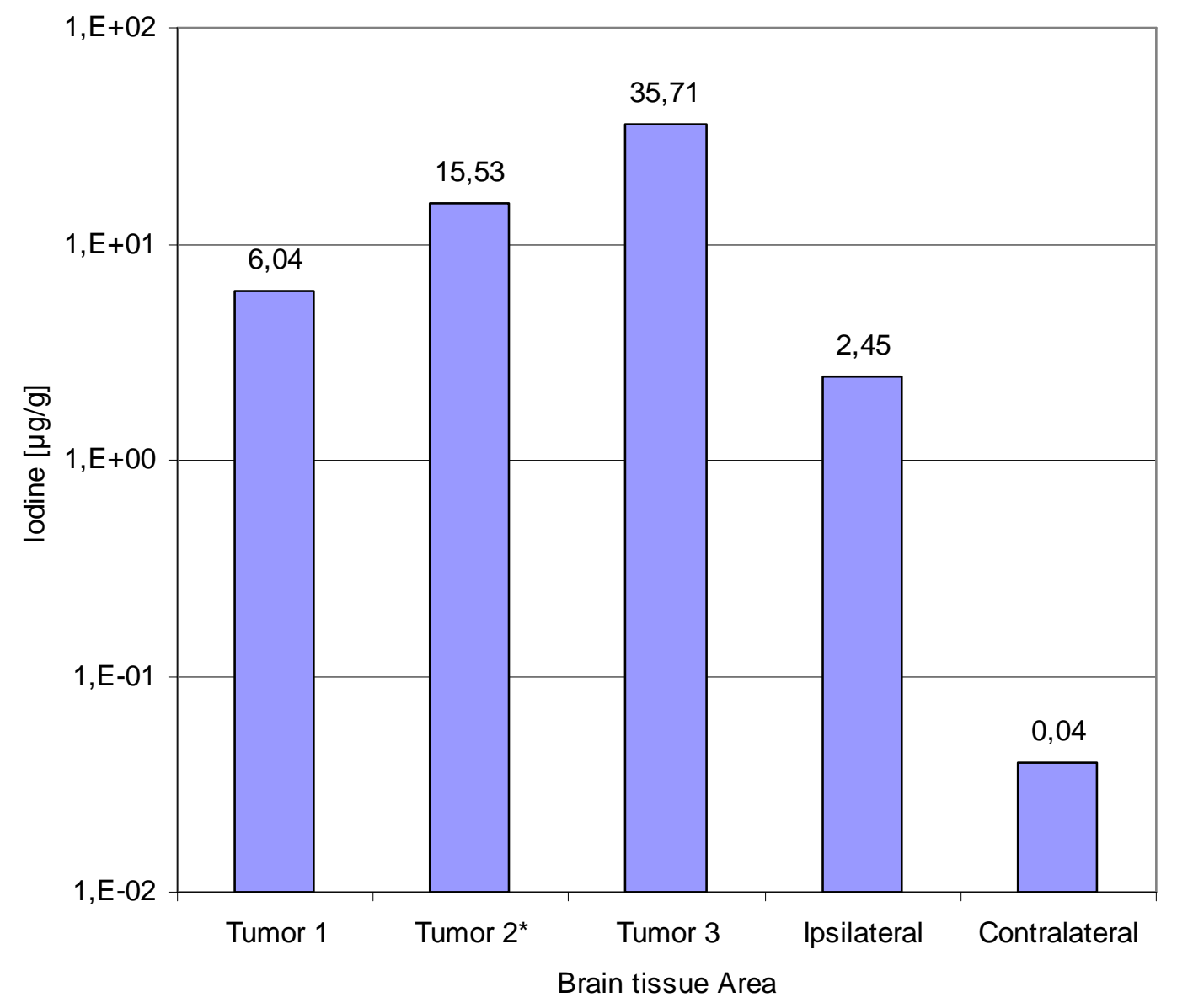


Figure 2 Iodine location at the subcellular level determined by Nano-SIMS analysis. The F98 glioma-bearing rat received an intratumoral injection of IUdR during 6 days by the means of osmotic pump. Panel (a), corresponds to a light microscopy view of a brain section stained with toluidine blue. The underlined part in panel (a) is the tumor brain area chosen for Nano-SIMS analysis. The panels (b), (c), (d) and (e) represent the corresponding Nano-SIMS analysis of respectively $\mathrm{CN}^{-}, \mathrm{P}^{-}, \mathrm{S}^{-}$and $\mathrm{I}^{-}$ions in this tumor brain area. Grey scale: white is corresponding to low concentrations or absence of the ion detected; black is corresponding to high concentrations of the ion detected.
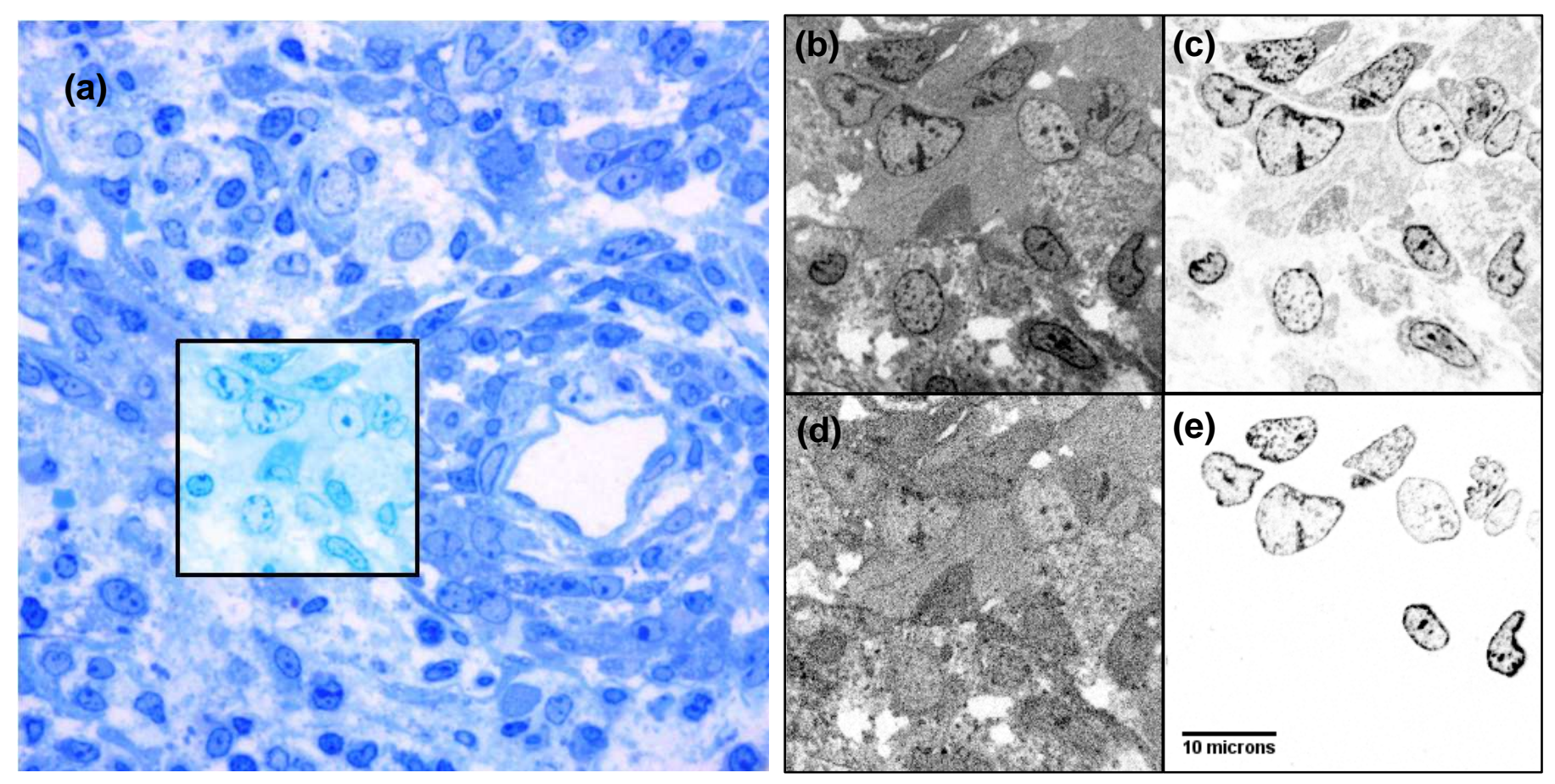
Figure 3 Kaplan Meier survival curves for F98 glioma-bearing rats after chemo-radiotherapy.

Survival times in days after tumor implantation have been plotted for untreated animals $(\times)$, infusion of ${ }^{127} \mathrm{IUdR}$ with osmotic pump $20 \mathrm{mg} / \mathrm{mL}$ alone $(\triangle)$, irradiation alone (single fraction of $\left.15 \mathrm{~Gy}\right)(\square)$, or in combination with ${ }^{127} \mathrm{IUdR}$ delivered by osmotic pump $20 \mathrm{mg} / \mathrm{mL}(\boldsymbol{\square})$. IUdR was administered for 6 days starting 7 days after tumor implantation. X-ray dose was delivered in a single fraction on day 14 after tumor implantation. Note: in the IUdR group, 2 rats died at the anesthesia and were not included in the analysis.




Figure 4 Synchrotron Computed Tomography. Ten consecutive CT images (slice thickness: 1mm) of the rat head of two representative animals: A) Untreated animal, imaged 18 days after tumor implantation, survival time: 21 days; the tumor is clearly visible on six slices with a tumor size index of $\approx 180 \mathrm{~mm}^{3}$. B) Group "IUdR alone"; imaged on day $17^{\text {th }}$ after tumor implantation; survival time: 51 days. The tumor was no longer detectable after IUdR infusion over 6 days (B), even with an optimized gray level windowing.

A



B




Figure 5 Tumor growth versus time for the different treatments. Tumor volumes measured using the CT images for a subset of rats in each group: Untreated animals $(\times) n=11$, infusion of ${ }^{127} I U d R$ with osmotic pump $20 \mathrm{mg} / \mathrm{mL}$ alone $(\triangle) \mathrm{n}=6$, irradiation alone (single fraction of $15 \mathrm{~Gy})(\square) \mathrm{n}=5$, or in combination with ${ }^{127} \mathrm{IUdR}$ with osmotic pump $20 \mathrm{mg} / \mathrm{mL}(\boldsymbol{\square}) \mathrm{n}=5$. IUdR was administrated for 6 days starting 7 days after tumor implantation. The line corresponds to an exponential fit of the "untreated group" survival data.

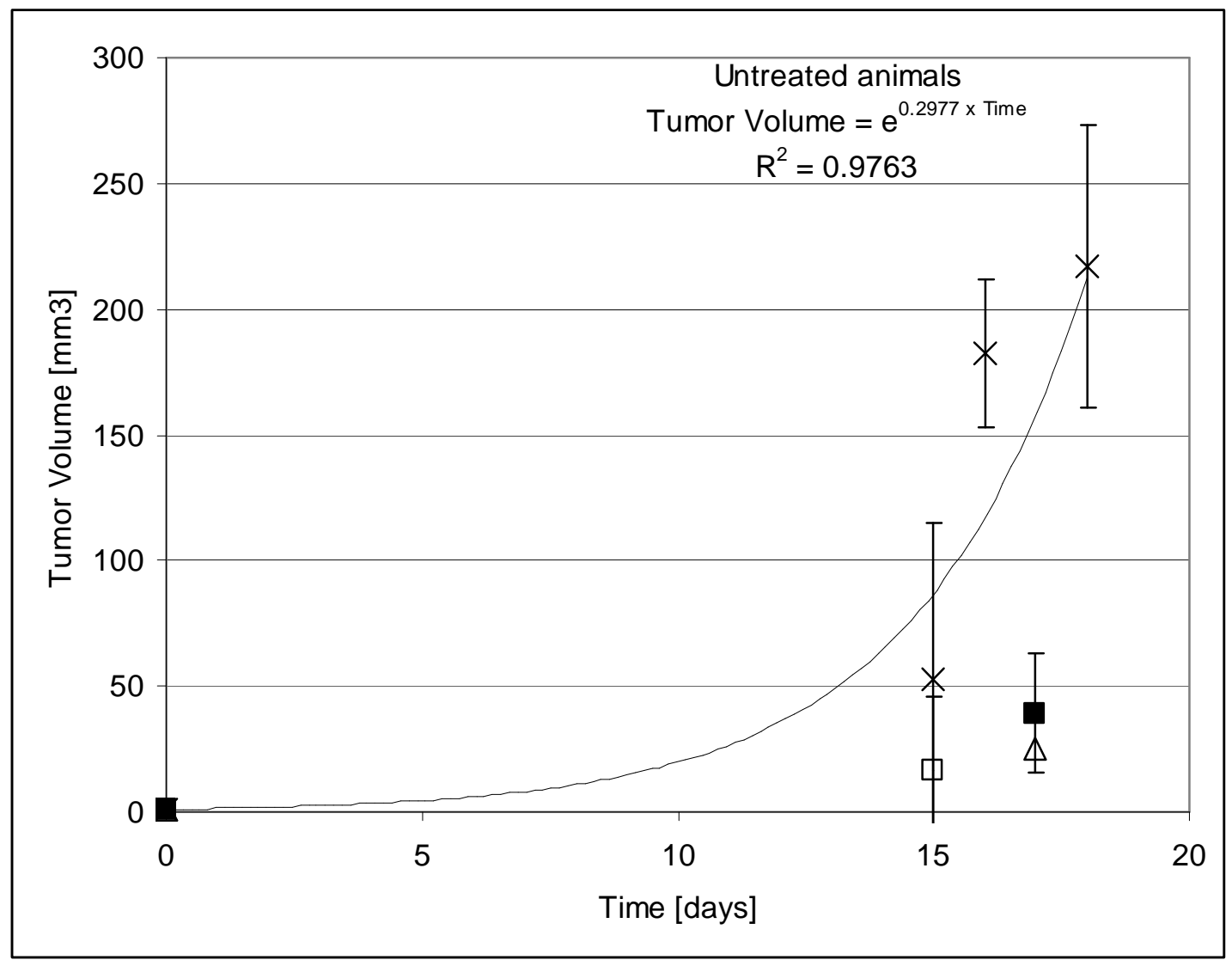

